Supplement of Atmos. Chem. Phys., 20, 8315-8349, 2020

https://doi.org/10.5194/acp-20-8315-2020-supplement

(c) Author(s) 2020. This work is distributed under

the Creative Commons Attribution 4.0 License.

(c) (1)

Supplement of

\title{
Modulation of radiative aerosols effects by atmospheric circulation over the Euro-Mediterranean region
}

Pierre Nabat et al.

Correspondence to: Pierre Nabat (pierre.nabat@meteo.fr)

The copyright of individual parts of the supplement might differ from the CC BY 4.0 License. 


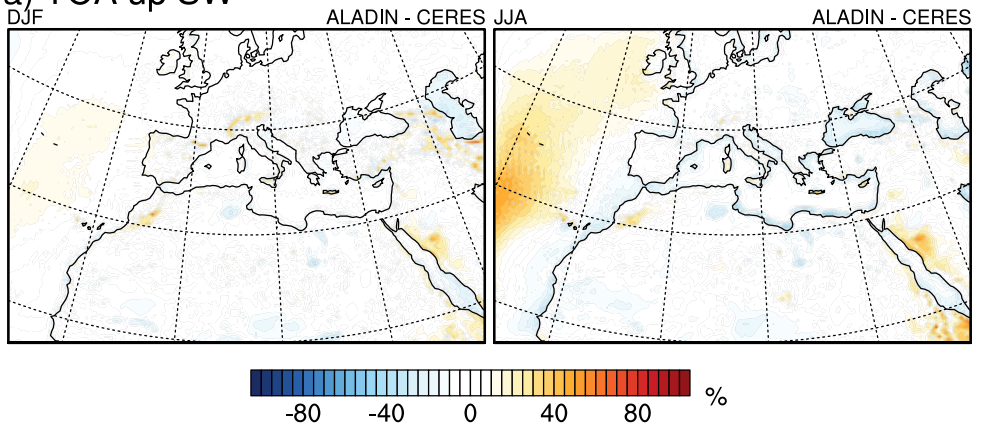

\section{b) TOA up LW}

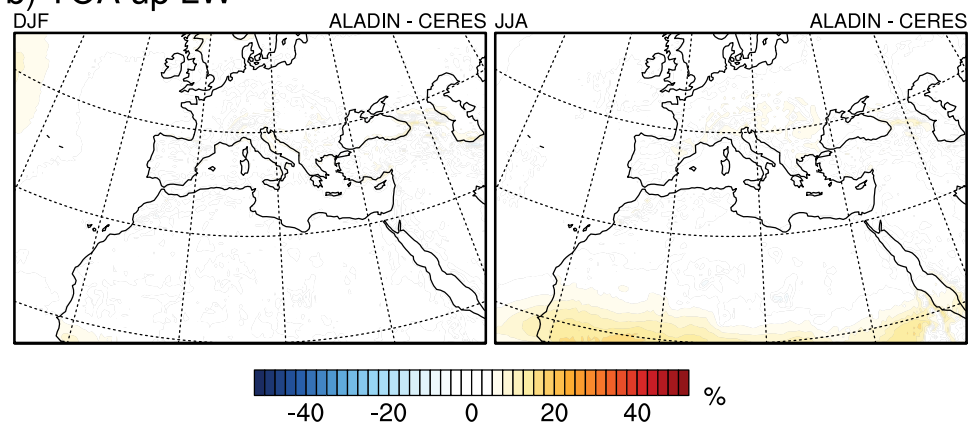

\section{c) Surf down SW}

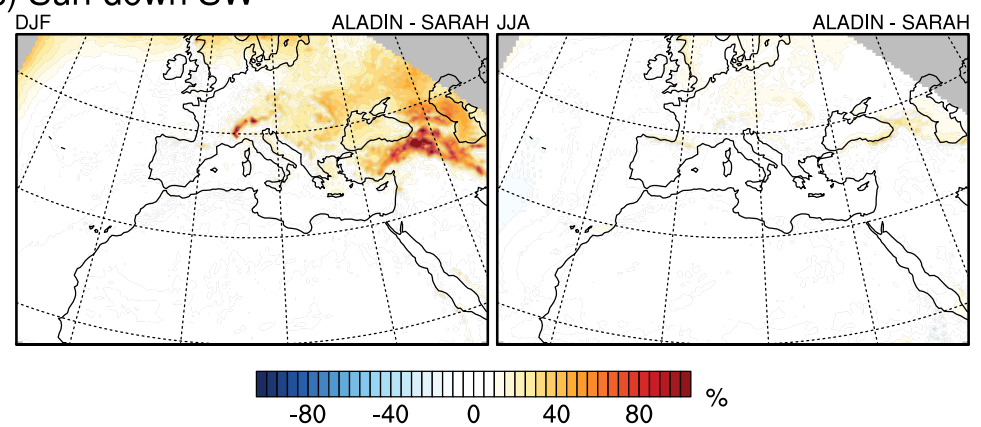

\section{d) Surf down LW}

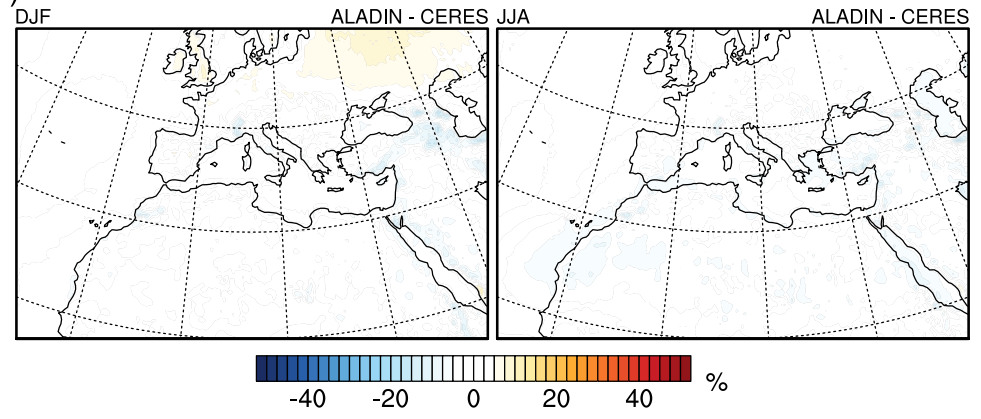

Figure S1. Winter (DJF, left) and summer (JJA, right) average relative differences (in \%) between ALADIN and satellite data for shortwave (SW) and longwave (LW) radiation at the top of the atmosphere (upward fluxes, a for SW, b for LW) and at the surface (downward fluxes, $c$ for SW, d for LW). Satellite data used here are CERES (2000-2016) in a, b and d, as well as SARAH (1983-2015) in c. 
ALADIN - MODIS
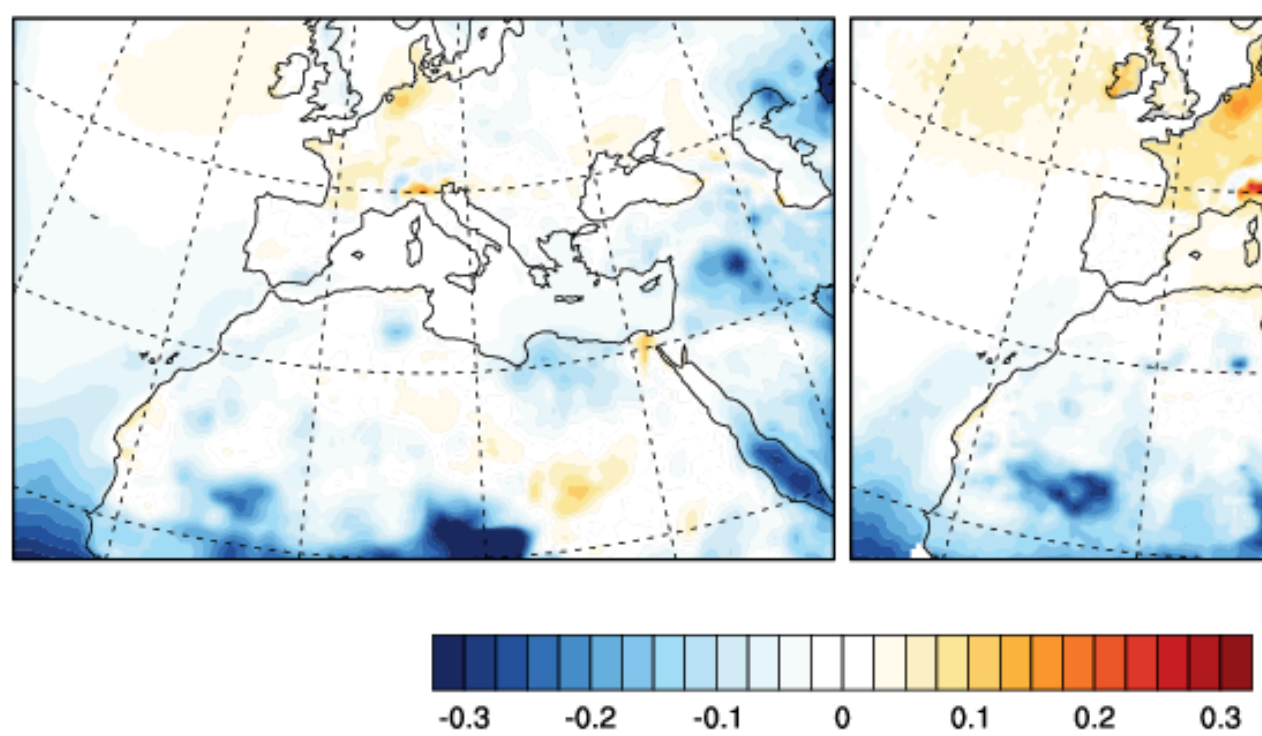

ALADIN - MISR

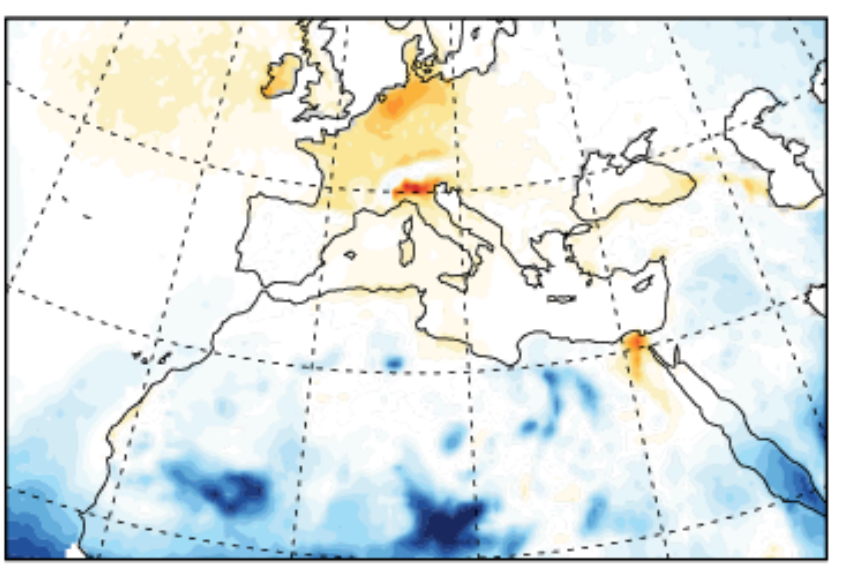

Figure S2. Annual average AOD difference (at $550 \mathrm{~nm}$ ) over the period 2003-2017 between ALADIN and satellite data (MODIS on the left, MISR on the right). 


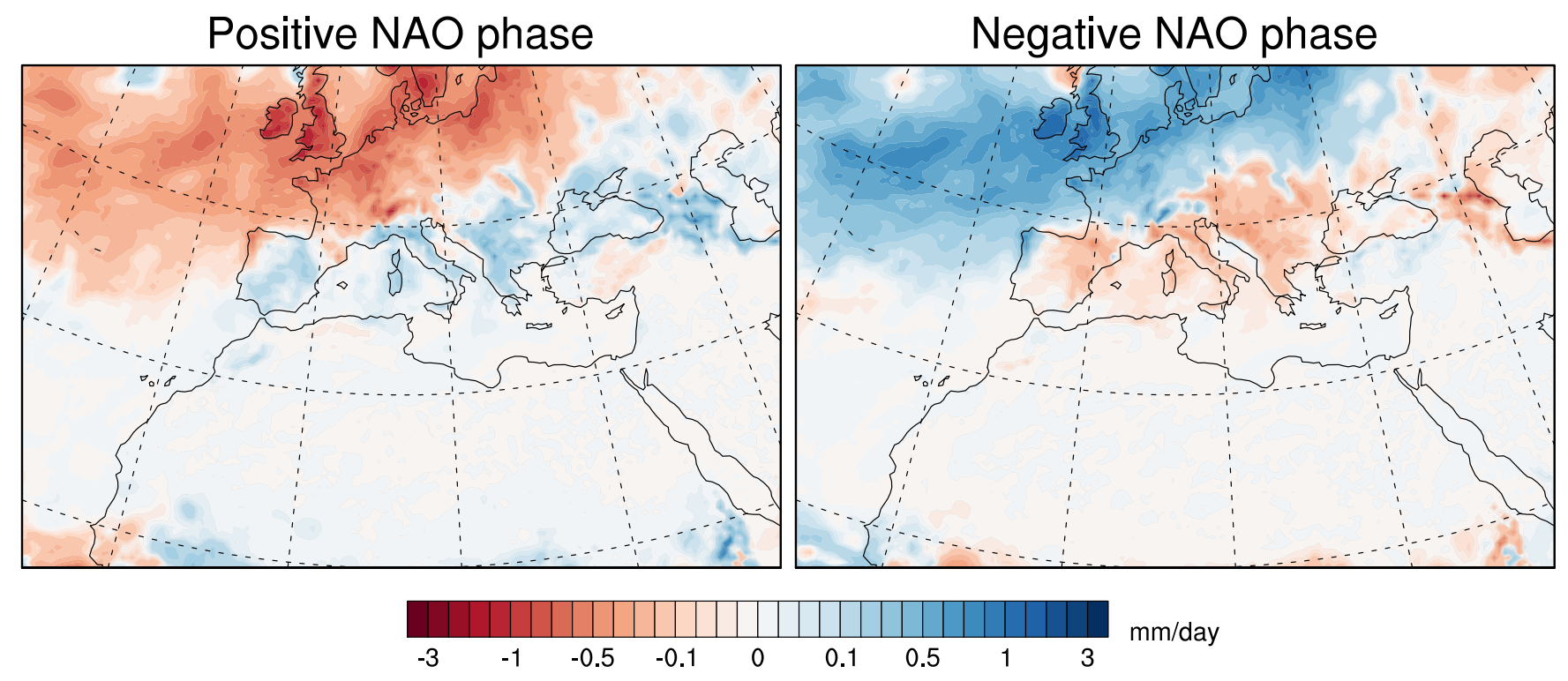

Figure S3. Averaged precipitation anomalies (mm/day) during the positive (left) and negative (right) phase of NAO, simulated by ALADIN in summer (JJA). 

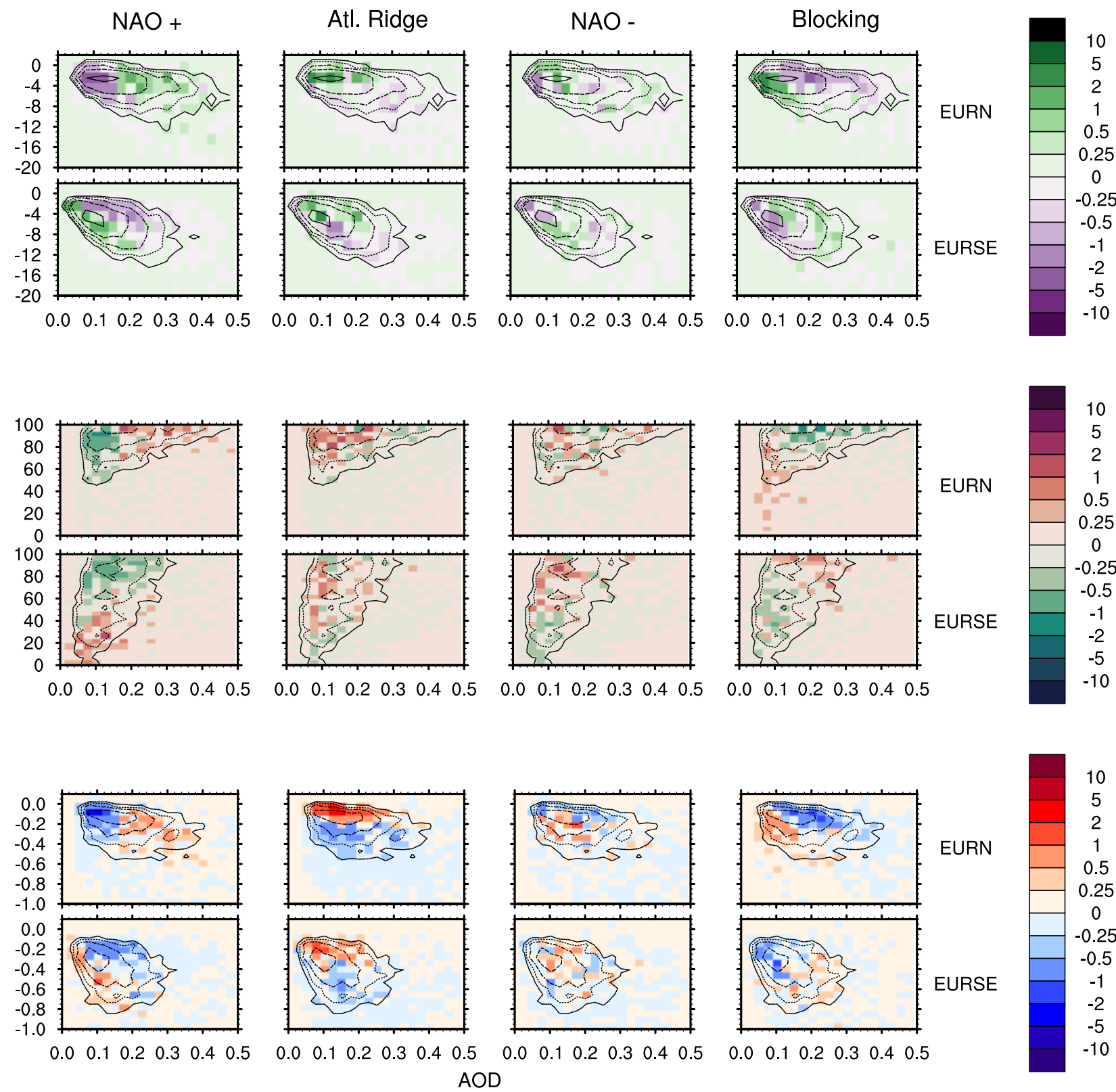

Figure S4. Probability distribution functions in function of AOD at $550 \mathrm{~nm}$ in winter (DJF) of the aerosol impact on surface SW downward radiation (top panel, in $\mathrm{W} \mathrm{m}^{-2}$, calculated as the difference between ALD-AER and ALD-NO), cloud cover (middle panel, in \%), and the aerosol impact on near-surface temperature (bottom panel, in ${ }^{\circ} \mathrm{C}$, calculated as the difference between ALD-AER and ALD-NO). The black lines represent the average (the values are $0.25,0.5,1.0,2.0$ and 10.0 in this order), while the colours present the anomalies of this distribution for each weather regime. These figures are calculated for the two regions EURN and EURSE (shown in Fig. 15). 

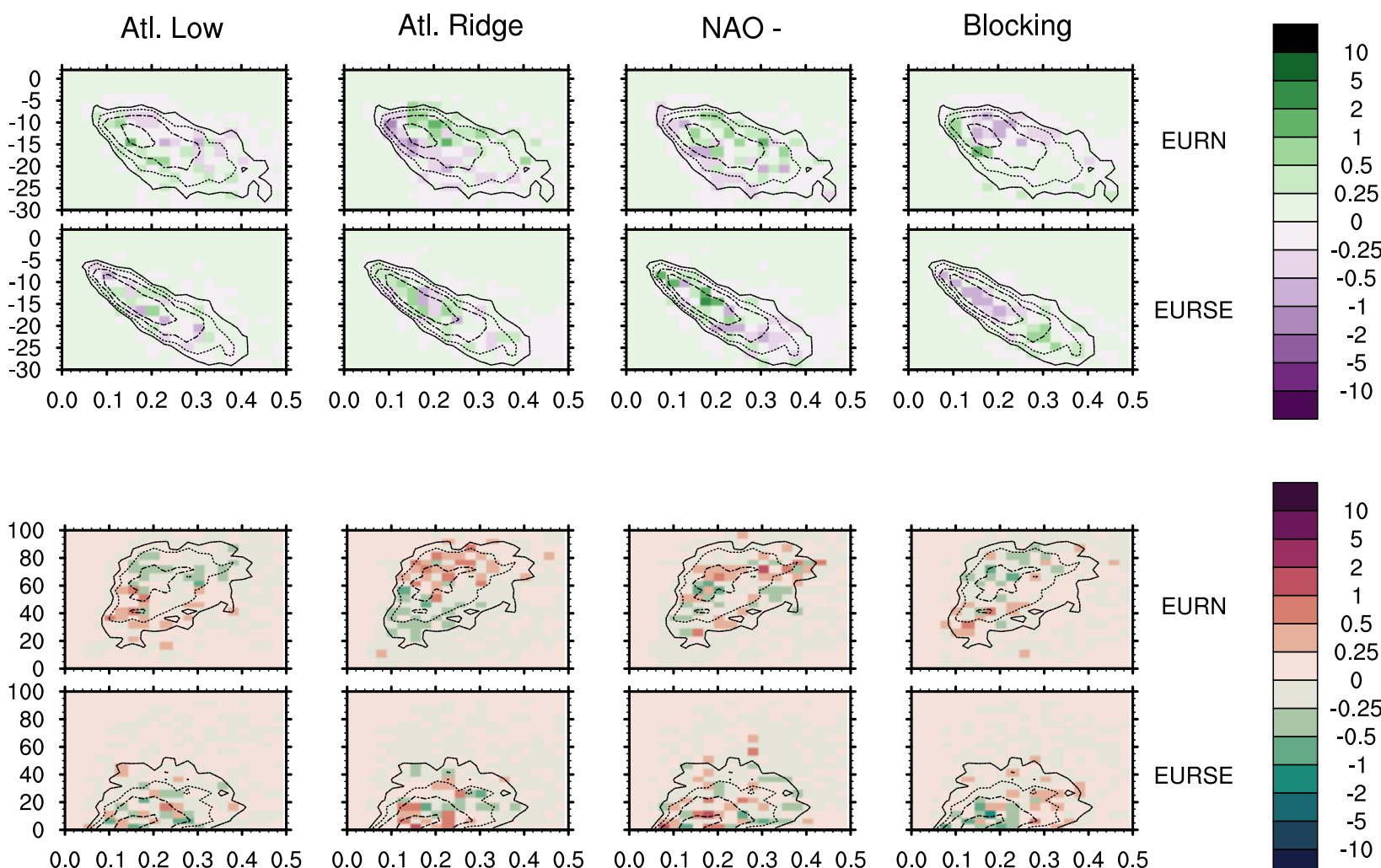

EURN
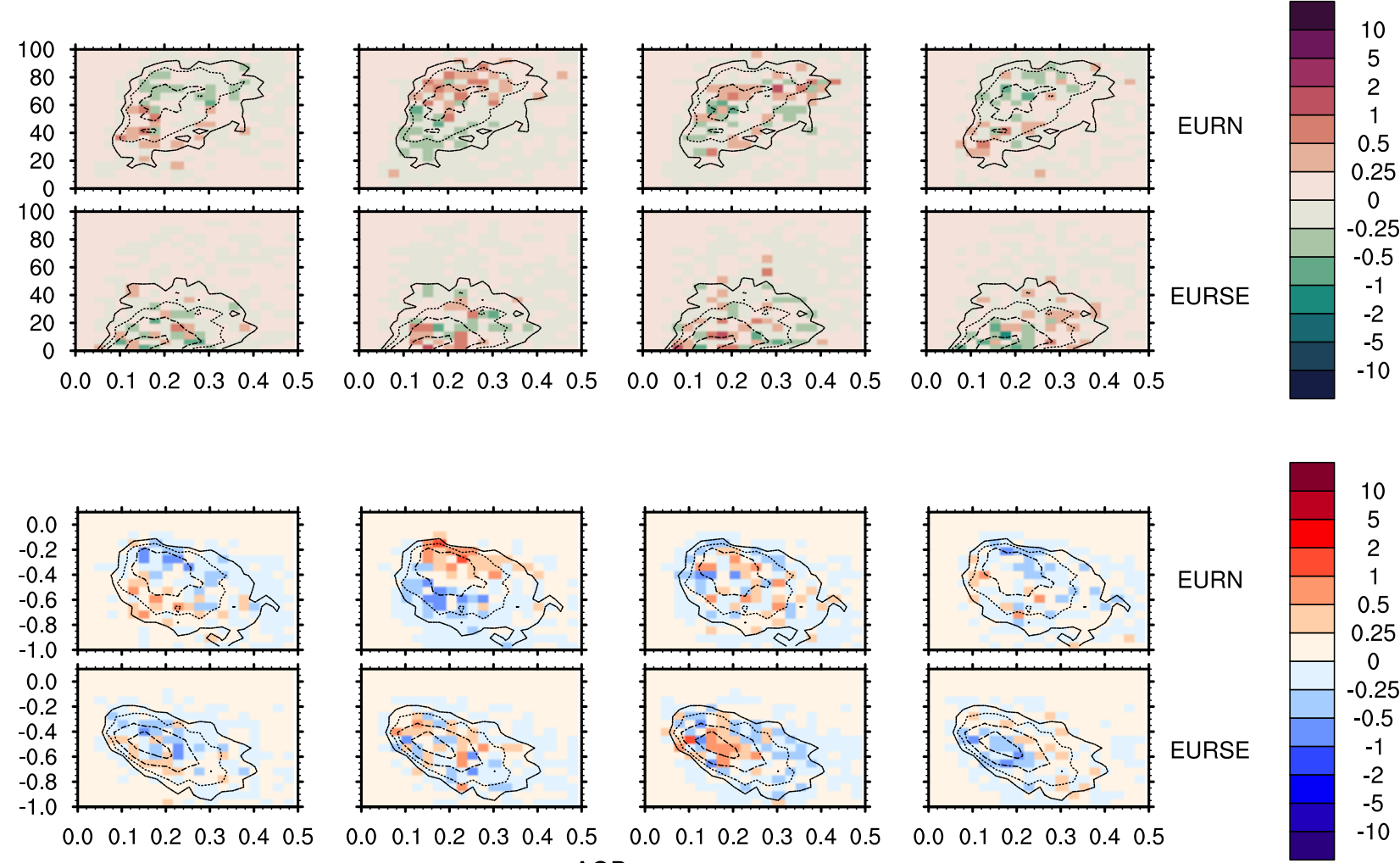

Figure S5. Same as Figure S4 but for summer (JJA). 